\title{
Crescimento, partição de fotoassimilados e produção de rizomas em taro cultivado sob sombreamento artificial
}

\author{
Ancélio Ricardo de O Gondimi ; Mário Puiatti²; Paulo R Cecon²; Fernando L Finger ${ }^{2}$ \\ ${ }^{1}$ UNESP/FCAV, Depto. Produção Vegetal, 14884-900 Jaboticabal-SP; ${ }^{2}$ UFV, Deptos. Fitotecnia e Informática, 36570-000 Viçosa-MG; \\ anceliogondim@hotmail.com
}

\section{RESUMO}

O cultivo associado é uma alternativa para culturas de ciclo longo e propriedades com limitação de área. Todavia, para o estabelecimento de associações, há necessidade de conhecer a tolerância das espécies ao sombreamento. O trabalho objetivou avaliar o crescimento de parte aérea, partição de fotoassimilados e produção de rizomas em plantas de taro 'Japonês' cultivadas sob intensidades e períodos de sombreamento artificial. Utilizou-se o delineamento de blocos ao acaso, com 13 tratamentos e quatro repetições. Os tratamentos foram constituídos de quatro intensidades de sombreamento (controle $=$ pleno sol; 18; 30 e 50\% de sombra, mantidos durante o ciclo todo), além da implementação das intensidades de sombra de 18; 30 e $50 \%$, em três períodos (inicial $=0$ a 3; intermediário $=3$ a 6 e final = 6 a 9 meses). Aos 60; 90; 120; 150; 180; 210; 240 e 270 dias após o plantio (dat), avaliou-se crescimento de planta e partição de massa entre órgãos e aos 270 dat a produção de rizomas. Plantas sob sombreamento, sobretudo nas maiores intensidades e durante o ciclo todo, apresentaram maior produção de biomassa de parte aérea e de rizomas-mãe e filhos pequenos, em detrimento de rizomasfilho grandes, médios e comerciáveis. A intensidade de 18\% de sombra, durante todo o ciclo ou nos períodos inicial e intermediário, foi a que menos afetou o desenvolvimento das plantas e produção de biomassa de rizomas-filho comerciáveis.

Palavras-chave: Colocasia esculenta, restrição de luz, rendimento, consorciação.

\begin{abstract}
Growth, assimilated partition and yield of taro corms 'Japonês' under different intensity and shading periods

Intercropping systems between different crops is considered an alternative for farms with limited area. But, for the establishment of these systems, it is fundamental to know the tolerance of the species to light restriction. The growth of the aerial portion and corm yield of 'Japanese' taro cultivated under different levels and periods of shading were determined in this study. The experiment was arranged in four random replicates, with 13 treatments. The experiment was composed of 13 treatments constituted of four levels of shading (control = full sunlight; $18 ; 30$ and $50 \%$ of shading, maintained during the whole cycle), and the $18 ; 30$ and $50 \%$ of shading in three periods (initial $=0$ - 3 months; middle cycle $=3-6$ months; and final $=6-9$ months). Plants under light restriction during the whole cycle had, in particular for the higher light restriction, a higher growth of aerial portion and yield of corm (mother rhizome) and small cormels, smaller number of commercial cormels per plant, yield of commercial cormels, and large and medium cormels. The 18\% light restriction for the whole cycle and for the initial and middle cycle affected less the total and commercial yield.
\end{abstract}

Keywords: Colocasia esculenta, artificial shading, yield, intercropping.

(Recebido para publicação em 26 de setembro de 2006; aceito em 7 de agosto de 2007)

$\mathrm{O}$ taro [Colocasia esculenta (L.) Schott] é uma hortaliça rizomatosa amilácea da família Araceae, conhecida no centro-sul do Brasil por "inhame" (Pedralli et al., 2002). No mundo, em 2005, foram cultivados com taro 1.841 mil ha, com produção de 10.587 mil toneladas e produtividade de 5,7 tha ${ }^{-1}$ (FAO, 2006). No Brasil, o cultivo e a importância econômica do taro cresceu muito na última década, sobretudo nos estados de Minas Gerais, Espírito Santo e Rio de Janeiro. Minas Gerais é um dos maiores produtores, obtendo, no ano de 2000, produção de 22.018 t e produtividade média de $20 \mathrm{t} \mathrm{ha}^{-1}$; todavia a produtividade varia muito entre os municípios produtores, havendo a necessidade de desenvolver tecnologias para sua melhoria (Mascarenhas \& Resende, 2002).
Além do potencial produtivo, a cultura do taro é considerada rústica por ser pouco exigente em tratos culturais, normalmente dispensando o uso de fertilizantes e de defensivos, constituindose em cultura apropriada para agricultores com pouco nível tecnológico, fato normalmente observado em nível de agricultura familiar. Todavia, esses produtores têm em comum a limitação de área física, o que dificulta a exploração da cultura do taro em razão do longo ciclo cultural (média de nove meses). Para situações dessa natureza, a associação de culturas torna-se uma importante alternativa, pois possibilita aumento da eficiência do uso da terra por ampliar, antecipar e diversificar as fontes de renda (Santos, 1998; Puiatti et al., 2000).

A busca por aumento em produtividade requer a compreensão da fisiologia do desenvolvimento da cultura, dos impactos dos fatores bióticos e abióticos envolvidos no crescimento e desenvolvimento bem como do manejo desses fatores (Goenaga, 1995). A luz é fator determinante da produtividade; além da produção de biomassa, interfere na morfologia, exportação e distribuição de assimilados. Plantas de taro sob limitação de luz apresentam aumento do índice de área foliar (Puiatti et al., 2000) e esse índice é importante para estimar o rendimento em Colocasia (Roychowdhury, 1995). Em associações de plantas a tolerância dessas ao sombreamento constitui-se em fator-chave, e sua ausência tem sido a causa do insucesso de associações quando há sombreamento excessivo de uma espécie em decorrência do crescimento acentuado de outra (Santos, 1998). 
Considerando que a irradiância é um dos mais importantes fatores determinantes da produtividade das plantas (Taiz \& Zeiger, 1998), características de crescimento são utilizadas para inferir o grau de tolerância das espécies à baixa disponibilidade de luz, uma vez que o crescimento pode refletir a habilidade de adaptação da espécie às condições de radiação do ambiente (Naves et al., 1994). Porém, o efeito do sombreamento sobre o crescimento e produtividade de determinada espécie depende da intensidade e da duração, somados ao estádio de desenvolvimento das plantas (Barrella, 2003).

Apesar de cultivado sob luz direta (Rubatzky \& Yamaguchi, 1997), o taro é tradicionalmente explorado em consórcio com coco, milho e outras culturas em alguns países da América Central (Goenaga, 1995), demonstrando apresentar certa tolerância ao sombreamento. A possível tolerância ao sombreamento, associada ao ciclo cultural longo, são características que vislumbram a possibilidade da associação do taro com outras culturas de maior porte. Todavia, pesquisas envolvendo a tolerância do taro ao sombreamento são limitadas (Oliveira, 2004). Portanto, determinar a intensidade e a época de sombreamento tolerado pela cultura, torna-se de fundamental importância como subsídio para o estabelecimento de associação do taro com culturas de maior porte. Objetivou-se caracterizar o crescimento da planta, partição de fotoassimilados e produção de rizomas do taro 'Japonês' cultivado sob intensidades e períodos de sombreamento.

\section{MATERIAL E MÉTODOS}

O experimento foi implementado na Horta da UFV, de 04/10/2004 a 04/07/ 2005. O solo, Argissolo Vermelho-Amarelo Câmbico, textura argilosa, apresentava os valores: $\mathrm{pH}\left(\mathrm{H}_{2} \mathrm{O}\right)=5,7 ; \mathrm{H}+$ $\mathrm{Al}^{+3}=2,97 ; \mathrm{P}=41,9$ e $\mathrm{K}=81 \mathrm{mg} \mathrm{dm}^{-3}$; $\mathrm{Ca}^{+2}=2,8 \mathrm{e} \mathrm{Mg}^{+2}=0,7 \mathrm{cmol}_{\mathrm{c}} \mathrm{dm}^{-3}$; matéria orgânica $=20,8 \mathrm{dag} \mathrm{kg}^{-1}$. Os valores médios mensais de temperaturas mínima, máxima e média, registrados em termohigrômetro (Icel, modelo HT208) colocado à altura do dossel da planta, nas quatro intensidades de sombreamento, estão na Figura 1. O solo, após aração e gradagem foi sulcado em linhas espaçadas de $1,0 \mathrm{~m}$, com profundidade de $0,12 \mathrm{~m}$, seguido da distribuição das mudas e do fechamento dos sulcos. Foram utilizados rizomasfilho do taro 'Japonês' (BGH 5925), com massa média de 100 g, obtidos do banco de germoplasma de hortaliças da UFV.

O experimento constou de 13 tratamentos, delineamento de blocos ao acaso, com quatro repetições. Os tratamentos foram constituídos de quatro intensidades de sombreamento $(\mathrm{Sol}=\mathrm{con}$ trole; 18; 30 e 50\% de sombra, mantidas durante o ciclo todo da cultura), além da implantação das intensidades de sombra de 18; 30 e 50\% em três períodos (inicial $=0$ a 3 meses; intermediário $=3$ a 6 meses; e final $=6$ a 9 meses). As intensidades de sombra foram obtidas com malhas Sombrite ${ }^{\circledR}$ colocadas cerca de $0,50 \mathrm{~m}$ acima do dossel, sendo elevadas conforme crescimento das plantas. A parcela constou de seis linhas, espaçadas de $1,0 \times 0,30 \mathrm{~m}$, com 3,0 m de comprimento. Considerou-se útil as quatro fileiras centrais, excluindo-se 0,60 m das extremidades. Não foi realizada adubação de plantio nem de cobertura. O controle das plantas daninhas foi realizado com o auxílio de enxada aos 21; 59; 79; 114 e 199 dias após o plantio (DAP). Na ausência de chuvas, e até 30 dias antes da colheita, foram realizadas irrigações semanais, por aspersão, aplicando-se em cada irrigação, lâmina de água de cerca de $40 \mathrm{~mm}$.

A partir de 60, até 270 DAP, mensalmente, colheu-se uma planta por repetição, sendo avaliada: área foliar (limbo), massa seca de limbo, pecíolo, rizoma-mãe, rizomas-filho e total por planta, comprimento do pecíolo e número de folhas/planta. A área foliar foi obtida em medidor eletrônico, modelo LiCor LI-3100; o comprimento do pecíolo pela distância da base da planta até a inserção do pecíolo no limbo e o número de folhas pela contagem de todas as folhas com potencial de realizar fotossíntese. A massa seca (MS) foi obtida após secagem em estufa de circulação de ar forçada a $70^{\circ} \mathrm{C}$ até peso constante. De posse dos dados de produção de massa, calculou-se a partição percentual de fotoassimilados (MS) entre as estruturas da planta.

Nove meses após o plantio (270 DAP), dez plantas por repetição foram colhidas e avaliadas quanto à produção de rizomas (massa e número). Os rizomas-mãe (RM) foram separados e os rizomas-filho classificados com base no diâmetro transversal, de acordo com Puiatti et al. (1990), nas classes filho grande (FG), médio (FM), pequeno (FP) e refugo (REF). A produtividade total consistiu do somatório das produtividades de rizomas-mãe e de todas as classes de rizomas-filho. Considerou-se comerciáveis (PC) o somatório das classes FG + FM + FP.

Os dados foram submetidos às análises de variância, teste de média e regressão. Características de produção de rizomas tiveram as médias de cada tratamento comparadas com a média do controle (sol) utilizando o teste de Dunnett a 5\% de probabilidade. Características de crescimento de parte aérea e de produção de rizomas dos tratamentos sob intensidades de sombra constante durante o ciclo todo foram submetidas à análise de regressão sendo os modelos das equações escolhidos com base na significância dos coeficientes de regressão, utilizando-se o teste “ $t$ ”, nos coeficientes de determinação e no fenômeno biológico.

\section{RESULTADOS E DISCUSSÃO}

Crescimento de planta - O sombreamento proporcionou menores valores de temperaturas máxima, mínima e média do ar, sendo a redução proporcional à intensidade de sombra, com maior amplitude para temperatura máxima (Figura 1). Exceto para número de folhas por planta e MS total, verificouse efeito de tratamento $(\mathrm{P}<0,05)$ para todas as características de crescimento avaliadas ao longo do ciclo (Figura 2; Tabela 1), evidenciando que a intensidade e a época de sombreamento influenciaram no crescimento das plantas.

O sombreamento promoveu modificações na morfologia das plantas ao longo do ciclo, com aumento da área foliar (AF) e alongamento do pecíolo, sendo esses aumentos mais pronunciados nos tratamentos que receberam som- 


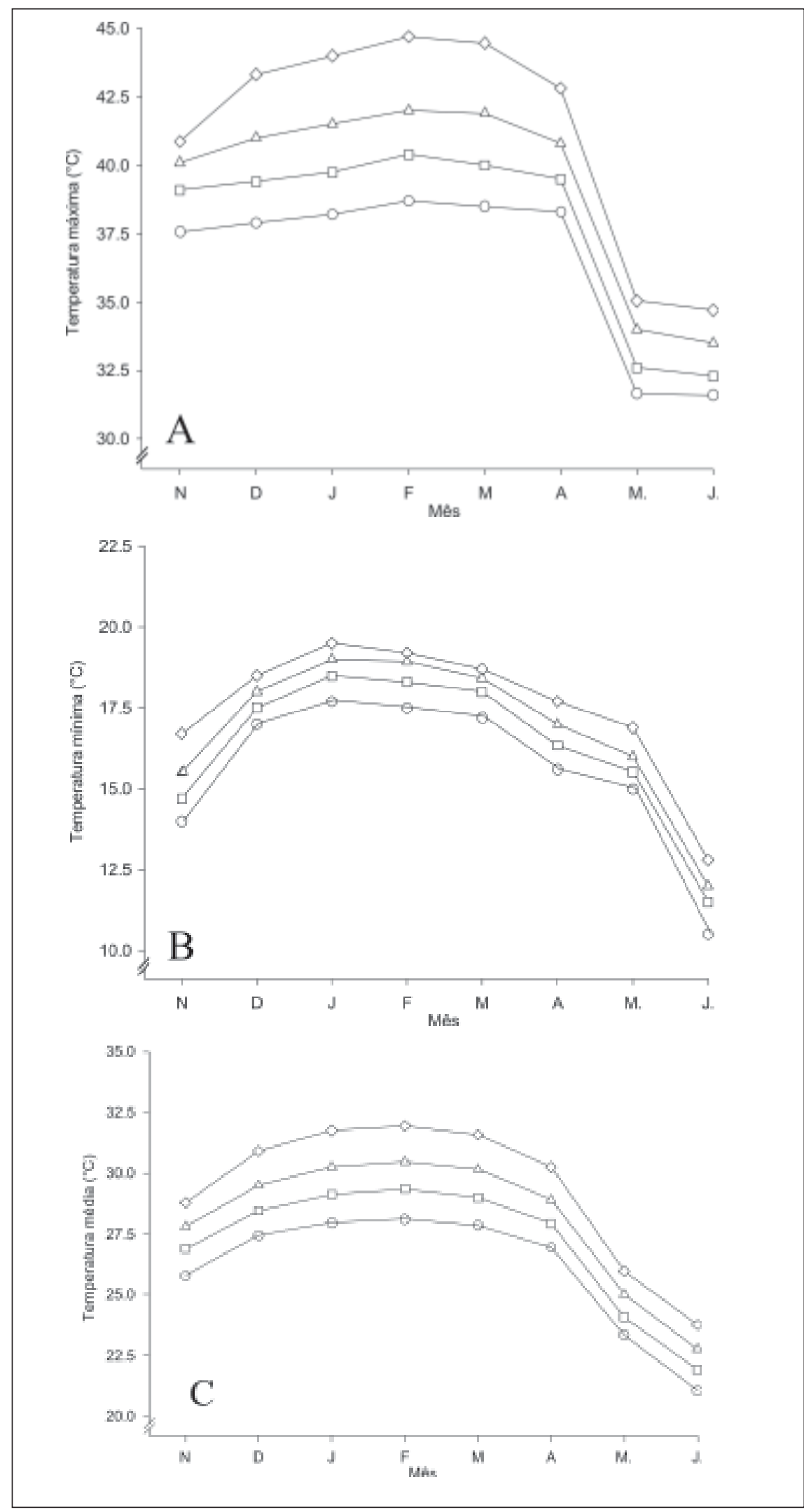

Figura 1. Médias mensais das temperaturas $\left({ }^{\circ} \mathrm{C}\right)$ máxima $(\mathrm{A})$, mínima (B) e média (C) do ar registradas nos tratamentos a pleno sol $(-\bigcirc-$ ) e sob as telas sombrites de $18 \%(-\triangle-)$, $30 \%(-\square-)$ e $50 \%(-0-)$, de novembro/2004 a junho/2005 (average temperatures $\left({ }^{\circ} \mathrm{C}\right)$ maxim (A), minim (B) and intermediate (C) of the air registrated for treatments under full sunlight $(-\bigcirc-)$ ) and under shading of $18 \%(-\triangle-)$, 30\% ( $\square-)$ and $50 \%(-0-)$, from november/2004 to june/2005). Viçosa, UFV, 2005. bra durante o ciclo todo e com maior intensidade (Figura 2A, H). O aumento da AF foi devido à expansão do limbo foliar, visto que não houve efeito de sombreamento sobre o número de folhas (Figura 2G). O máximo de AF ocorreu entre 90 e 120 DAP (Figura 2A) enquanto para comprimento de pecíolo, exceto para os tratamentos que receberam sombreamentos na fase inicial, maiores valores ocorreram entre $120 \mathrm{e}$ 150 DAP (Figura 2H). Esses resultados evidenciam que, em uma primeira fase, as plantas expandiram a lâmina foliar e, à medida que a restrição de luz foi se acentuando com o ciclo, devido ao autosombreamento, as plantas passaram a investir em crescimento do pecíolo à procura de luz, sobretudo aquelas dos tratamentos sob maior restrição de luz.

Maiores valores estimados de AF foram obtidos nas intensidades de sombra de $50 \%$ (50T), seguidos de $30 \%$ (30T) durante o ciclo todo; por outro lado, plantas a pleno sol (controle) durante o ciclo todo, e aquelas submetidas ao sombreamento no período final (18F, 30F e 50F), foram as que apresentaram menor AF, sobretudo nos primeiros 180 DAP (Figura 2A). Esses resultados indicam uma adaptação morfológica da planta na tentativa de aumentar a área de captação dos raios solares sob restrição de luz. Resultados semelhantes, em AF, foram obtidos por Oliveira (2004) em plantas de taro 'Japonês' submetidas à restrição de luz em intensidade de até $75 \%$.

Plantas submetidas ao sombreamento na fase inicial apresentaram queima das folhas após a retirada das malhas, levando à diminuição da $\mathrm{AF}$ (Figura 2A). A necrose ocorreu em razão da exposição repentina dessas plantas à luz direta, visto que a retirada das malhas ocorreu em pleno verão (Figura 1). Necrose de folhas do taro no verão em regiões tropicais foi observado por Puiatti et al. (2000) e Oliveira (2004) e são devidas à fotoxidação da clorofila causada pelo excesso de radiação incidente (Taiz \& Zeiger, 1998). Espécies de plantas apresentam mecanismos para atenuar esse tipo de injúria, alterando a relação entre clorofilas e carotenóides e, ou, incrementando a síntese de carotenóides, como forma de reduzir a 

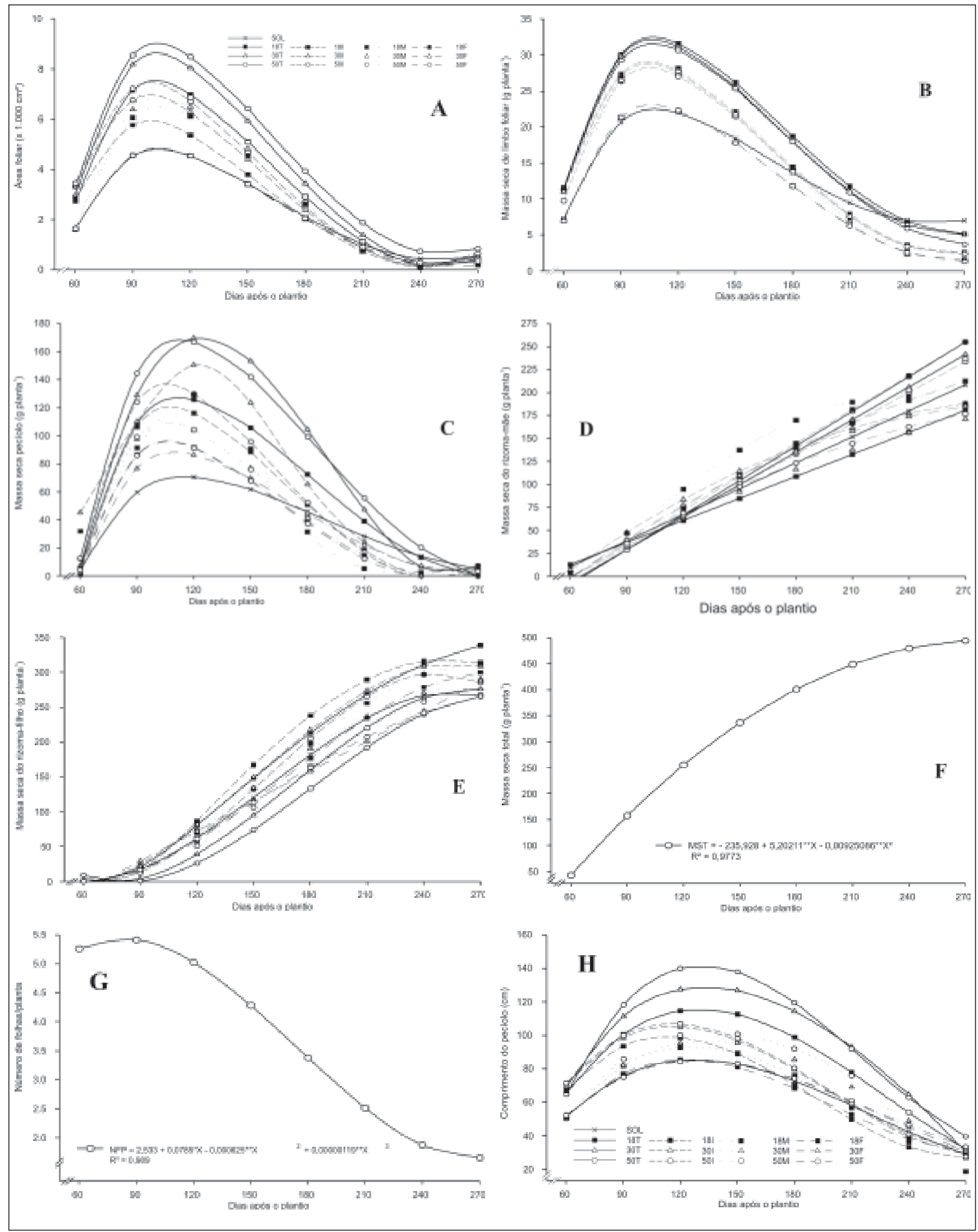

Figura 2. Estimativa da área foliar (A) e de massa seca de limbo (B), pecíolo (C), rizoma-mãe (D), rizomas-filho (E), total (F), número de folhas/planta $(\mathrm{G})$ e do comprimento do pecíolo $(\mathrm{H})$ ao longo do ciclo, de plantas de taro 'Japonês' cultivadas sob intensidades e períodos de sombreamento artificial (vide legenda) (estimated leaf área (A) and dry mass of the limb (B), petiole (C), mother rhizome (D), small cormels (E), total (F), number of leaves/plant (G) and lenght of petiole (H), during the cycle of taro 'Japonês' plants, cultivated under intensity and artificial shading periods). Viçosa, UFV, 2005. 
Tabela 1. Equações ajustadas da área foliar (勺ิ), massa seca de limbo, pecíolo e de rizomasmãe e filhos $(\widehat{y})$ e comprimento do pecíolo $(\widehat{y})$ de plantas de taro 'Japonês', em função dos dias após o plantio (X), cultivadas sob intensidades e períodos de sombreamento e os respectivos coeficientes de determinação (Adjusted equations of leaf area $(\widehat{y})$, dry mass of the lymb, petiole and mother rhizome and small corms $(\widehat{y})$ and lenght of the petiole $(\widehat{y})$ and taro 'Japonês' plants, depending on the days after planting date (X), cultivated under intensity and artificial shading periods and the respective determination coefficients). Viçosa, UFV, 2005

\begin{tabular}{|c|c|c|}
\hline Tratamento & Área foliar (AF) & $\mathbf{R}^{\mathbf{2}}$ \\
\hline SOL & $Y=-87727,5+23103,4^{*} X 0,5-1862,3^{*} X+47,6^{* *} X^{1,5}$ & 0,9829 \\
\hline $18 \mathrm{~T}$ & $Y=-140690,0+37272,1^{* *} X 0,5-3023,8^{* *} X+77,8^{* *} X^{1,5}$ & 0,9858 \\
\hline 30T & $Y=-162371,0+42866,9^{* *} X 0,5-3467,6^{* *} X+88,9^{* *} X^{1,5}$ & 0,9910 \\
\hline $50 \mathrm{~T}$ & $Y=-160558,0+42403,2^{* *} X 0,5-3420,7^{* *} X+87,5^{* *} X^{1,5}$ & 0,9869 \\
\hline 181 & $Y=-103260,0+27896,8^{* *} X 0,5-2296,4^{* *} X+59,8^{* *} X^{1,5}$ & 0,9792 \\
\hline 301 & $Y=-122734,0+33200,8^{* *} X 0,5-2739,4^{* *} X+71,5^{* *} X^{1,5}$ & 0,9612 \\
\hline 501 & $Y=-134482,0+36320,4^{* *} X 0,5-2996,9^{* *} X+78,3^{* *} X^{1,5}$ & 0,9411 \\
\hline $18 \mathrm{M}$ & $Y=-133517,0+34877,4^{* *} X 0,5-2806,5^{* *} X+71,8^{* *} X^{1,5}$ & 0,9653 \\
\hline $30 \mathrm{M}$ & $Y=-142465,0+37179,6^{* *} X 0,5-2990,6^{* *} X+76,5^{* *} X^{1,5}$ & 0,9758 \\
\hline $50 \mathrm{M}$ & $Y=-153526,0+40045,0^{* *} X 0,5-3223,2^{* *} X+82,5^{* *} X^{1,5}$ & 0,9813 \\
\hline $18 \mathrm{~F}$ & $Y=-89284,8+23480,1^{* *} X 0,5-1889,3^{* *} X+48,2^{* *} X^{1,5}$ & 0,9813 \\
\hline $30 \mathrm{~F}$ & $Y=-89126,3+23457,4^{* *} X 0,5-1889,7^{* *} X+48,3^{* *} X^{1,5}$ & 0,9778 \\
\hline \multirow[t]{2}{*}{$50 \mathrm{~F}$} & $Y=-89183,8+23478,3^{* *} X 0,5-1892,2^{* *} X+48,4^{* *} X^{1,5}$ & 0,9786 \\
\hline & Massa seca do limbo foliar (MSL) & \\
\hline SOL & $Y=-357,47+92,89^{\star} X 0,5-7,35^{\star} X+0,18^{\star} X^{1,5}$ & 0,8988 \\
\hline $18 \mathrm{~T}$ & $Y=-489,27+126,94^{* *} X 0,5-9,95^{* *} X+0,25^{* *} X^{1,5}$ & 0,9674 \\
\hline $30 \mathrm{~T}$ & $?=-497,72+129,49^{*} \times 0,5-10,20^{*} X+0,25^{*} X^{1,5}$ & 0,9676 \\
\hline $50 \mathrm{~T}$ & $Y=-471,75+122,26^{* *} X 0,5-9,56^{* *} X+0,24^{* *} X^{1,5}$ & 0,9701 \\
\hline 181 & $Y=-463,39+121,66^{* *} X 0,5-9,68^{* *} X+0,24^{*} X^{1,5}$ & 0,9446 \\
\hline 301 & $Y=-463,54+121,63^{* *} X 0,5-9,68^{* *} X+0,24^{* *} X^{1,5}$ & 0,9436 \\
\hline 501 & $Y=-470,15+122,71^{* *} X 0,5-9,74^{*} X+0,24^{*} X^{1,5}$ & 0,9479 \\
\hline $18 \mathrm{M}$ & $Y=-551,37+142,48^{* *} X 0,5-11,28^{* *} X+0,28^{*} X^{1,5}$ & 0,9410 \\
\hline $30 \mathrm{M}$ & $Y=-541,77+139,97^{* *} X 0,5-11,08^{* *} X+0,28^{*} X^{1,5}$ & 0,9389 \\
\hline $50 \mathrm{M}$ & $Y=-540,52+139,74^{*} X 0,5-11,07^{*} X+0,28^{*} X^{1,5}$ & 0,9394 \\
\hline $18 \mathrm{~F}$ & $Y=-390,84+101,19^{*} \times 0,5-7,97^{*} X+0,19^{*} X^{1,5}$ & 0,9163 \\
\hline $30 \mathrm{~F}$ & $Y=-391,53+101,38^{*} X 0,5-7,98^{*} X+0,19^{*} X^{1,5}$ & 0,9168 \\
\hline \multirow[t]{2}{*}{$50 \mathrm{~F}$} & $Y=-392,54+101,64^{*} X 0,5-8,01^{*} X+0,19^{*} X^{1,5}$ & 0,9157 \\
\hline & Massa seca do pecíolo (MSP) & \\
\hline SOL & $Y=-1239,8+306,4^{*} X 0,5-23,1^{*} X+0,55^{* * *} X^{1,5}$ & 0,8786 \\
\hline $18 \mathrm{~T}$ & $Y=-2468,1+615,8^{*} X 0,5-47,1^{*} X+1,14^{*} X^{1,5}$ & 0,9231 \\
\hline $30 \mathrm{~T}$ & $Y=-577,9+14,3^{*} X-0,08^{*} X 2+0.00015^{*} X^{3}$ & 0,8750 \\
\hline $50 \mathrm{~T}$ & $Y=-3106,2+773,5^{\star *} X 0,5-58,9^{* *} X+1,42^{* *} X^{1,5}$ & 0,9731 \\
\hline 181 & $Y=-2892,2+737,8^{*} X 0,5-58,5^{* * *} X+1,48^{* * *} X^{1,5}$ & 0,7633 \\
\hline 301 & $Y=\operatorname{EXP}\left(0,002+0,08^{*} X-0,0004^{*} X 2+0,00000044^{*} X^{3}\right)$ & 0,8577 \\
\hline 501 & $Y=-3226,4+832,6^{* *} X 0,5-66,7^{*} X+1,70^{*} X^{1,5}$ & 0,9028 \\
\hline $18 \mathrm{M}$ & $Y=\operatorname{EXP}\left(-0,75+0,09^{*} X-0.00039^{*} X^{2}\right)$ & 0,9033 \\
\hline $30 \mathrm{M}$ & $Y=-2648,9+680,9^{* *} X 0,5-54,4^{* *} X+1,38^{* *} X^{1,5}$ & 0,9495 \\
\hline $50 \mathrm{M}$ & $Y=-2765,9+713,3^{* *} X 0,5-57,3^{* *} X+1,47^{* *} X^{1,5}$ & 0,9416 \\
\hline $18 \mathrm{~F}$ & $Y=-2309,4+594,5^{* *} X 0,5-47,6^{* *} X+1,21^{* *} X^{1,5}$ & 0,9662 \\
\hline $30 \mathrm{~F}$ & $Y=-1911,7+483,1^{* *} X 0,5-37,7^{* *} X+0,9^{* *} X^{1,5}$ & 0,9523 \\
\hline $50 \mathrm{~F}$ & $Y=-2327,1+598,1^{* *} X 0,5-47,8^{* *} X+1,22^{* *} X^{1,5}$ & 0,9791 \\
\hline
\end{tabular}

*; **; ***: respectivamente significativos a 5; 1 e 10\% de probabilidade, pelo teste " $\mathrm{t}$ " (*; $* *$; ***: respectively significant at $5 ; 1$ and $10 \%$ probability, "t" test). fotoxidação da clorofila (Hendry \& Price, 1993; Taiz \& Zeiger, 1998). Porém, parece que a habilidade adaptativa da planta de taro não é muito elevada ou a espécie ainda está em processo adaptativo para cultivo a pleno sol. Apesar disso, observaram-se alterações morfológicas com alongamento de pecíolo e expansão de limbo foliar sob sombreamento. Esses resultados são importantes, pois evidenciam que a planta possui ajuste do aparato fotossintético à intensidade de luz (Larcher, 2000), e essa característica deve ser considerada em sistemas de consórcio com cultura dominante.

O comportamento da massa seca do limbo (MSL) ao longo do ciclo foi semelhante ao da AF, com máximo compreendido entre 90-120 DAP (Figura 2B). Maiores valores estimados de MSL foram obtidos nas intensidades de sombra de 18 ; 30 e $50 \%$ durante o ciclo todo (18T, 30T e 50T); por outro lado, plantas a pleno sol durante o ciclo todo (SOL), e plantas submetidas às intensidades de sombra de 18 ; 30 e $50 \%$ na fase final (18F, $30 \mathrm{~F}$ e $50 \mathrm{~F}$ ), foram as que apresentaram menor MSL na fase de maior crescimento vegetativo (60-150 DAP).

Exceto pela magnitude entre tratamentos, o comportamento da massa seca do pecíolo (MSP) foi semelhante nas intensidades de sombra; porém, diferentemente da AF e da MSL, os máximos ficaram compreendidos entre 90-150 DAP (Figura 2C). Maiores valores estimados de MSP foram obtidos nos níveis de sombra de 50 e de $30 \%$ durante o ciclo todo (50T e $30 \mathrm{~T}$ ), e menor no controle (SOL) na fase de maior crescimento vegetativo.

Maior acúmulo de MS no rizomamãe (MSRM) ocorreu aos 270 DAP, exceto para a intensidade de $18 \%$ de sombra no período intermediário (18M) (Figura 2D; Tabela 1). Aos 270 DAP maiores valores estimados de MSRM foram obtidos nas intensidades de sombra de $18 \%$ no período inicial (18I) e de $50 \%$ e $30 \%$ no ciclo todo (50T e 30T). Valores elevados de massa de rizomamãe não são desejáveis, visto que esses têm baixo valor de comércio (Puiatti, 2002); além disso, podem competir com rizomas-filho por assimilados diminuindo a produção comercial (Goenaga \& Singh, 1992; Goenaga, 1995). 
Exceto pela diferença de magnitude e para os tratamentos SOL e sombreados durante o período inicial a 18 e $50 \%$ (18I e 50I), o comportamento da massa seca do rizoma-filho (MSRF) ao longo do ciclo de cultivo foi semelhante nas intensidades de sombra, com máximos entre 240 e 270 DAP (Figura 2E). Maior valor de MSRF foi obtido na intensidade de sombra de $18 \%$ durante ciclo todo (18T), e menor nas intensidades de 50\% e $30 \%$ ciclo todo (50T e 30T). Portanto, intensidades mais elevadas de restrição de luz não foram favoráveis ao acúmulo de MSRF. O tempo nublado durante os dias de chuva no verão pode ter acentuado o efeito sombreador das malhas, como observado no meloeiro por Pereira (2006). No Rio de Janeiro, Oliveira (2004) também verificou em taro 'Japonês' que a intensidade de sombreamento (75\%) retardou a formação de rizomas-filho e reduziu o número de rizomas produzidos por planta. Caesar (1980) também observou redução na produção de rizomas-filho na cv. Trinidad, tanto sob estresse de luz quanto hídrico. Redução no acúmulo de MS, causado por restrição de luz, também foi observado em raízes tuberosas de plantas de rabanete (Souza et al., 1999), de tubérculos de batata (Solanum tuberosum L.) (Gawronska \& Dwelle, 1989) e de raízes de cenoura (Hole \& Dearman, 1990).

Os tratamentos de sombra não exerceram efeito sobre o número de folhas por planta, alcançando máximo próximo dos 90 DAP, declinando até a colheita (Figura 2G). O decréscimo foi semelhante ao da AF, todavia iniciou antes, sobretudo do decréscimo no comprimento de pecíolo, indicando que, com o sombreamento, a planta priorizou a utilização das reservas no alongamento de pecíolo em detrimento da emissão de novas folhas. O pecíolo é o órgão que mais evidencia os efeitos da restrição de luz, tanto em MS (Figura 2C) quanto em comprimento (Figura 2H). Plantas a pleno sol apresentaram menor declínio de MSP e MSL na fase final do ciclo, possivelmente, em razão das temperaturas mais elevadas nesse ambiente (Figura 1). Esses resultados estão em conformidade com o observado por Goenaga (1995) nas cvs. Banca e Lilá, em condições semelhantes de clima.

Tabela 1. Continuação

\begin{tabular}{|c|c|c|}
\hline \multicolumn{2}{|c|}{ Tratamento } & \multirow[t]{2}{*}{$\mathbf{R}^{\mathbf{2}}$} \\
\hline & Massa seca do rizoma-mãe (MSRM) & \\
\hline$\overline{\mathrm{SOL}}$ & $Y=-45,92+0,94^{* *} X$ & 0,9398 \\
\hline $18 \mathrm{~T}$ & $Y=-34,86+0,79^{* *} X$ & 0,9591 \\
\hline $30 \mathrm{~T}$ & $Y=-77,12+1,18^{* *} X$ & 0,9703 \\
\hline $50 \mathrm{~T}$ & $Y=-83,9+1,25^{* *} X$ & 0,9676 \\
\hline $18 I$ & $Y=-74,56+1,22 * * X$ & 0,9880 \\
\hline 301 & $Y=-90,372+1,785^{*} X-0,00279^{* *} X^{2}$ & 0,9727 \\
\hline 501 & $Y=-68,64+1,12^{* *} X$ & 0,9822 \\
\hline $18 \mathrm{M}$ & $Y=441,4-163,67^{*} X 0,5+18,11^{* *} X-0,55^{* *} X^{1,5}$ & 0,9960 \\
\hline $30 \mathrm{M}$ & $Y=-79,74+1,41^{* *} X-0,00177^{* * *} X^{2}$ & 0,9615 \\
\hline $50 \mathrm{M}$ & $Y=-68,71+1,13^{* *} X$ & 0,9549 \\
\hline $18 \mathrm{~F}$ & $Y=-90,8856+1,60265^{* *} X-0,00177568^{*} X^{2}$ & 0,9923 \\
\hline $30 \mathrm{~F}$ & $Y=-103,901+1,86272^{* *} X-0,00293701^{*} X^{2}$ & 0,9835 \\
\hline \multirow[t]{2}{*}{$50 \mathrm{~F}$} & $Y=-84,8966+1,53042^{* *} X-0,00207925^{*} X^{2}$ & 0,9813 \\
\hline & Massa seca do rizoma-filho (MSRF) & \\
\hline$\overline{\mathrm{SOL}}$ & $Y=83,29-3,15^{*} X+0,033^{* *} X 2-0,0000705^{* *} X^{3}$ & 0,9944 \\
\hline $18 \mathrm{~T}$ & $Y=1141,56-340,266^{* * *} X 0,5+31,189^{* * *} X-0,818^{* * *} X^{1,5}$ & 0,9793 \\
\hline $30 \mathrm{~T}$ & $Y=155,8-4,68^{*} X+0,04^{*} X 2-0,000079^{*} X^{3}$ & 0,9843 \\
\hline $50 \mathrm{~T}$ & $Y=171,46-4,7^{* * *} X+0,037^{*} X 2-0,000069^{*} X^{3}$ & 0,9782 \\
\hline 181 & $Y=1911,51-563,917^{*} X 0,5+52,013^{*} X-1,44^{*} X^{1,5}$ & 0,9804 \\
\hline 301 & $Y=34,39-2,35 n s X+0,031^{* * *} X 2-0,000069^{* * *} X^{3}$ & 0,9753 \\
\hline 501 & $Y=133,25-4,63^{* * *} X+0,045^{*} X 2-0,000097^{*} X^{3}$ & 0,9829 \\
\hline $18 \mathrm{M}$ & $Y=45,85-2,36 n s X+0,028^{* * *} X 2-0,000059^{* * *} X^{3}$ & 0,9832 \\
\hline $30 \mathrm{M}$ & $Y=1015,79-305,154^{* * *} X 0,5+28,28^{* * *} X-0,75^{* * *} X^{1,5}$ & 0,9831 \\
\hline $50 \mathrm{M}$ & $Y=99,32-3,39^{*} X+0,033^{* *} X 2-0,000067^{* *} X^{3}$ & 0,9941 \\
\hline $18 \mathrm{~F}$ & $Y=72,02-2,74 n s X+0,028^{*} X 2-0,000057^{*} X^{3}$ & 0,9883 \\
\hline \multirow[t]{2}{*}{$30 \mathrm{~F}$} & $Y=-99,60+1,43^{* *} X$ & 0,9712 \\
\hline & Comprimento do pecíolo (cm) & \\
\hline$\overline{\mathrm{SOL}}$ & $Y=-54,71+2,53^{* *} X-0,014^{* *} X 2+0,000021^{*} X^{3}$ & 0,9713 \\
\hline $18 \mathrm{~T}$ & $Y=-84,15+3,53^{*} X-0,019^{*} X 2+0,000027^{* * *} X^{3}$ & 0,9516 \\
\hline 30T & $Y=-420,65+95,16^{* *} \times 0,5-4,12^{* *} X$ & 0,8829 \\
\hline $50 \mathrm{~T}$ & $Y=-164,61+5,45^{*} X-0,029^{*} X 2+0,000045^{* * *} X^{3}$ & 0,8976 \\
\hline 181 & $Y=-76,06+3,59^{* *} X-0,022^{*} X 2+0,000039^{*} X^{3}$ & 0,9525 \\
\hline 301 & $Y=-69,63+3,48^{*} X-0,021^{* * *} X 2+0,000035^{* * *} X^{3}$ & 0,8872 \\
\hline 501 & $Y=-74,35+3,62^{*} X-0,022^{*} X 2+0,000037^{* * *} X^{3}$ & 0,8952 \\
\hline $18 \mathrm{M}$ & $Y=-82,41+3,20^{* *} X-0,018^{* *} X 2+0,000026^{*} X^{3}$ & 0,9753 \\
\hline $30 \mathrm{M}$ & $Y=-69,56+2,83^{* *} X-0,014^{* *} X 2+0,000019^{*} X^{3}$ & 0,9793 \\
\hline $50 \mathrm{M}$ & $Y=-349,66+77,24 * * X 0,5-3,30 * * X$ & 0,9281 \\
\hline $18 \mathrm{~F}$ & $Y=-72,33+3,01^{* *} X-0,017^{*} X 2+0,000029^{*} X^{3}$ & 0,9466 \\
\hline $30 \mathrm{~F}$ & $Y=-46,12+2,32^{* *} X-0,012^{* *} X 2+0,000018^{*} X^{3}$ & 0,9775 \\
\hline $50 \mathrm{~F}$ & $Y=-46,75+2,34^{* *} X-0,013^{* *} X 2+0,000018^{*} X^{3}$ & 0,9736 \\
\hline
\end{tabular}

*; **; ***: respectivamente significativos a $5 ; 1$ e $10 \%$ de probabilidade, pelo teste "t" (*; **; ***: respectively significant at $5 ; 1$ and $10 \%$ probability, “t” test).

Plantas dos tratamentos que receberam sombreamento na fase inicial revelaram maior comprimento de pecíolo entre 90 e 120 DAP em razão das folhas emitidas após a retirada da restrição de luz aos 90 DAP, apresentarem menor comprimento de pecíolo (Figura $2 \mathrm{H}$ ). Resultados semelhantes foram obtidos por Puiatti et al. (2000) com taro 'Chi- nês', quando em cultivo consorciado com milho-doce, embora os máximos em altura e AF tenham ocorrido em ciclo mais avançado da cultura, fato explicado pela diferença de épocas de instalação dos cultivos. Nesse aspecto, o plantio tardio em regiões com baixas temperaturas no outono/inverno favorece as plantas alcançarem máximos em 
altura e área foliar mais precocemente em razão das plantas alcançarem o estádio de repouso à medida que há declínio da temperatura.

De modo geral, por volta dos 120 DAP deu-se o início ou acentuou-se o declinou em AF e no acúmulo de MSL e MSP (Figura 2A, B, C), coincidindo com o incremento de acúmulo de massa no rizoma-mãe e rizomas-filho (Figura 2D, E), enquanto o acúmulo de MS total teve comportamento quadrático (Figura 2F). No início, a parte aérea (limbo e pecíolo) foi a maior responsável pela MS total; com o declínio de MS da parte aérea, rizomas-mãe e filho passaram a ser os maiores responsáveis pelo acúmulo de MS na planta. Comportamento semelhante foi encontrado por Puiatti et al. (1992) com o taro 'Chinês' e 'Japonês’ e por Goenaga (1995) com cvs. Blanca e Lilá.

Partição de fotoassimilados - A partição percentual de fotoassimilados entre limbo, pecíolo e rizomas-mãe e filhos nas plantas cultivadas nos tratamentos com intensidades de sombra constante durante o ciclo todo, e os respectivos modelos de regressão ajustados, estão contidos na Figura 3 e Tabela 2. Exceto as diferenças em magnitude, a partição de fotoassimilados ao longo do ciclo foi semelhante nos tratamentos. Até os $60 \mathrm{DAP}$, as plantas alocaram maior percentual de MS para limbo e pecíolo. No início do crescimento esse tipo de resposta é esperado, pois as plantas tornam-se autotroficamente menos dependentes dos assimilados presentes no material propagativo (Goenaga, 1995). Porém, o efeito de sombra foi manifestado com mais evidência pelo pecíolo, comparado ao limbo (Figura 3A, B). Aos 60 DAP os acúmulos estimados de MSL, nos tratamentos controle, 18; 30 e 50\% de sombra foram, respectivamente, de 41,7; 47,9; 40,1 e 49,1\%, enquanto em MSP foi de 38,4; 44,7; 47,4 e 52,7\% da MS total. Entre 60 e 120 DAP ocorrem máximos de acúmulo de MSP; aos 90 DAP o pecíolo acumulava 40,6; 52,0; 59,1 e 60,0\% nos tratamentos controle, 18 ; 30 e $50 \%$ de sombreamento, respectivamente.

Entre 90 e 120 DAP, concomitantemente com o declínio de acúmulo de MSP, ocorreu incremento

Tabela 2. Equações ajustadas para massa seca de limbo, pecíolo, rizoma-mãe e rizomasfilhos $(\widehat{y})$ de plantas de taro 'Japonês', em função dos dias após o plantio (X), cultivadas sob sol (controle) e intensidades sombreamento de 18, 30 e 50\% durante o ciclo todo, e os respectivos coeficientes de determinação (Adjusted equations of lymb dry mass, petiole, mother rhizome and small cormels ( $\widehat{y})$, of taro 'Japonês' plants, depending on the days after planting date (X), cultivated under sunlight (standard) and intensity of shading of 18; 30 and $50 \%$ of shading during all growing period and the respective determination coefficients). Viçosa, UFV, 2005.

\begin{tabular}{|c|c|c|}
\hline Tratamento & Massa seca do limbo & $\mathbf{R}^{\mathbf{2}}$ \\
\hline SOL & $Y=450889,3735^{* *} X^{-2,26842}$ & 0,9889 \\
\hline $18 \%$ & $Y=847539,60 * * X^{-2,38867}$ & 0,9722 \\
\hline $30 \%$ & $Y=434130,2017^{* *} X^{-2,26912}$ & 0,9463 \\
\hline \multirow[t]{2}{*}{$50 \%$} & $Y=1336872,531^{* *} X^{-2,49461}$ & 0,9261 \\
\hline & Massa seca do pecíolo & \\
\hline$\overline{\mathrm{SOL}}$ & $Y=\operatorname{EXP}\left(2,85+0,021^{* *} X-0,000128^{*} X^{2}\right)$ & 0,9762 \\
\hline $18 \%$ & $Y=\operatorname{EXP}\left(2,67+0,028^{*} X-0,000153^{* *} X^{2}\right)$ & 0,9940 \\
\hline $30 \%$ & $Y=\operatorname{EXP}\left(2,71+0,027^{*} X-0,000131^{*} X^{2}\right)$ & 0,9475 \\
\hline \multirow[t]{2}{*}{$50 \%$} & $Y=\operatorname{EXP}\left(3,07+0,022^{*} X-0,000118^{*} X^{2}\right)$ & 0,9726 \\
\hline & Massa seca do rizoma-mãe & \\
\hline$\overline{\mathrm{SOL}}$ & $Y=20,22+0,080^{* * *} X$ & 0,7183 \\
\hline $18 \%$ & $Y=11,39+0,086^{*} X$ & 0,9562 \\
\hline $30 \%$ & $Y=\quad 6,27+0,146^{* * *} X$ & 0,8278 \\
\hline \multirow[t]{2}{*}{$50 \%$} & $Y=-4,77+0,213^{*} X$ & 0,9723 \\
\hline & Massa seca do rizoma-filho & \\
\hline$\overline{\mathrm{SOL}}$ & $Y^{0,5}=-3,10+0,093^{* *} X-0,00019^{*} X^{2}$ & 0,9809 \\
\hline $18 \%$ & $Y^{0,5}=-4,54+0,104^{*} X-0,00021^{*} X^{2}$ & 0,9958 \\
\hline $30 \%$ & $Y^{0,5}=-6,04+0,111^{*} X-0,00023^{* * *} X^{2}$ & 0,9450 \\
\hline $50 \%$ & $Y^{0,5}=-5,53+0,101 * X-0,00020^{* * *} X^{2}$ & 0,9037 \\
\hline
\end{tabular}

*,** $\mathrm{e}^{* * *}$ : respectivamente significativos a 5,1 e $10 \%$ de probabilidade, pelo teste " $\mathrm{t}$ " (*; **; ***: respectively significant at $5 ; 1$ and $10 \%$ probability, "t" test).

na taxa de acúmulo de MSRF (Figura 3B, D). Esse comportamento está em conformidade com pesquisa de Hashad et al. (1956), que verificaram que o pecíolo funciona como dreno temporário para fotoassimilados até $\mathrm{O}$ armazenamento nos rizomas. A partir de 120 DAP, até o final do ciclo, ocorreram decréscimos gradativos e semelhantes nos tratamentos de sombra, quanto ao acúmulo de MSL. Dos 210 aos 270 DAP, as taxas de acúmulo de MS foram baixas em ambos (limbo e pecíolo), correspondendo à maturação das plantas.

O acúmulo de MSRM, ao longo do ciclo, teve comportamento linear, com maiores taxas nos tratamentos com maiores intensidades de sombra (Figura 2C). Entretanto, para os rizomas-filho, as taxas foram variáveis; baixa no início (até 100/110 DAP) e após os 210 DAP e acentuada no intervalo entre essas (Figura 2D). Diferentemente do rizoma-mãe, proporcionalmente maior acúmulo de MSRF foi observado sob menores intensidades de sombra (18\% e SOL), demonstrando que, nesses ambientes, as plantas foram mais eficientes para alocar assimilados para os rizomas-filho. Aos 210 DAP, os rizomas-filho acumulavam 64,5; 64,8; 50,8 e 47,1\% da MS total, nos tratamentos SOL, $18 ; 30$ e $50 \%$ de sombreamento, respectivamente. Nesse aspecto, o tempo nublado pode ter acentuado o efeito de restrição de luz, prejudicando o acúmulo de MSRF, como observado em meloeiro por Pereira (2006). Esses resultados também estão em concordância com os de Goenaga (1995), que observou acúmulo acima de $50 \%$ da MS nos rizomas-filho a partir de 210 DAP.

Apesar do particionamento entre órgãos ter apresentado comportamento semelhante nos tratamentos de sombra, plantas controle e $18 \%$ de sombra ao longo do ciclo todo alocaram, proporcionalmente, menos MSP e mais MSRF; além disso, embora tenham acumulado 


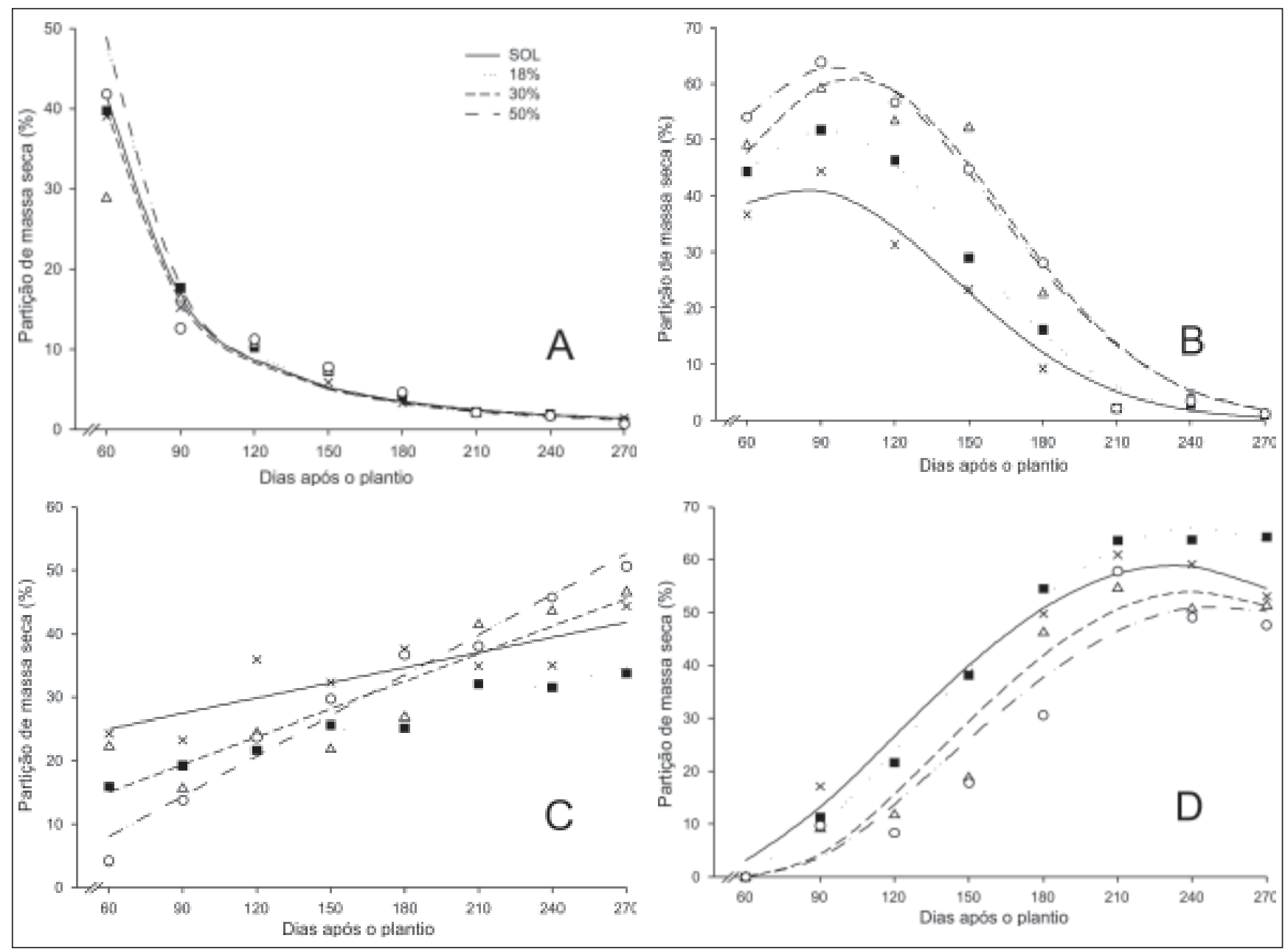

Figura 3. Estimativa da partição percentual de massa seca no limbo (A), pecíolo (B), rizoma-mãe (C) e rizomas-filho (D) ao longo do ciclo, em plantas de taro 'Japonês' cultivadas sob sol (controle) e intensidades sombreamento de 18; 30 e $50 \%$ durante o ciclo todo (vide legenda) (estimated partition percentual of dry mass of the lymb (A) petiole (B), mother rhizome (C), small cormels (D), during the cycle of taro 'Japonês' plants, cultivated under sunlight (standard) and shading intensities of 18; 30 and 50\% during the whole cycle). Viçosa, UFV, 2005.

mais MSRM na fase inicial, em razão da menor taxa de acúmulo a partir dos 150 DAP (18\% de sombra) e dos 210 DAP (SOL), plantas desses ambientes continham menor acúmulo de MSRM que os tratamentos com 30 e $50 \%$ de sombra. Aos 270 DAP, os rizomas-filho apresentaram acúmulo estimado de 66,6; 67,8; 51,3 e 51,3\% da MS total nos tratamentos controle (SOL), 18; 30 e $50 \%$ de sombreamento, respectivamente (Figura 3D).

Independente do tratamento pode-se identificar quatro estádios de crescimento (E1, E2, E3 e E4), com base no acúmulo de MS. O E1, que vai do plantio até $60 \mathrm{DAP}$, é caracterizado por pequeno acúmulo de MS total; o E2, que vai dos 60 até por volta dos 90-120 DAP, é caracterizado por rápido crescimento da parte aérea com elevada taxa de AF e de acúmulo de MSL e MSP (Figura 2A, B, C). Dos 60 aos 90 DAP a taxa de acúmulo foi de 2,18 e 5,05 g de $\mathrm{MS} \mathrm{dia}^{-1}$ planta $^{-1}$ na parte aérea (limbo + pecíolo), respectivamente para os tratamentos controle e $50 \%$ de sombra o ciclo todo. O E3, que vai de 120 DAP até 210 DAP, é caracterizado pela redução da AF e da MS acumulada na parte aérea devido à diminuição da emissão de novas folhas e a senescência natural das folhas e de elevado acúmulo de MSRM e MSRF. Dos 120 aos 210 DAP a taxa de acúmulo MSRM foi de 0,94 e 1,25 g de MS plan$\mathrm{ta}^{-1} \mathrm{dia}^{-1}$, respectivamente, para os tratamentos controle e $50 \%$ de sombra o ciclo todo; para os rizomas-filho, esses tratamentos, nesse mesmo período, apresentaram taxas de acúmulo de 1,84 e 1,74 MS planta-1 dia $^{-1}$, respectivamente, evidenciando a menor eficiência de acúmulo de MS no rizoma-filho sob $50 \%$ de sombra. E4, que vai dos 210 até o final do ciclo, é caracterizado por taxas decrescentes no acúmulo de MS nos rizomas-filho e estabilização do acúmulo na parte aérea. Portanto, o incremento em MS total na planta é devido, principalmente, à parte aérea no E2; à parte aérea e rizomas no E3 e rizomas no E4. Esse modelo de crescimento está em concordância com trabalhos em várias aráceas (Goenaga \& Singh, 1992; Goenaga, 1994, 1995; Puiatti et al., 1992, 2000), apesar de muitos desses considerarem apenas três estádios, juntando E1 com E2 ou E3 com E4.

Produção de rizomas - Tratamentos de sombra nas maiores intensidades (50\% e 30\%) durante o ciclo todo, favoreceram o acúmulo de reservas no rizoma-mãe resultando em menor nú- 
Tabela 3. Valores médios de produtividade total (PT) e comerciável (PC), de massa média de rizomas comerciáveis (MRC), número de rizomas comerciáveis por planta (NRC), produtividade de rizomas-mãe (RM) e de filhos grande (FG), médio (FM), pequeno (FP) e refugo (REF) e coeficiente de variação de plantas de taro 'Japonês', aos 270 DAP, cultivadas sob intensidades e períodos de sombra (average values of total yield (PT) and commercial yield (PC), average mass of commercial rhizomes (MRC), number of commercial rhizomes/plant (NRC), yield of mother rhizomes (RM) and great rhizomes (FG), intermediate (FM), small (FP) and discard (REF), and variation coefficient of taro ‘Japonês’ plants, 270 DAP, cultivated under intensity and shading periods). Viçosa, UFV, 2005.

\begin{tabular}{|c|c|c|c|c|c|c|c|c|c|c|}
\hline \multirow{2}{*}{$\begin{array}{l}\text { Intensidade } \\
\text { de sombra } \\
(\%)\end{array}$} & \multirow{2}{*}{$\begin{array}{l}\text { Período de } \\
\text { sombra (dias) }\end{array}$} & PT & PC & \multirow{2}{*}{$\begin{array}{c}\text { MRC } \\
\text { (g/rizoma) }\end{array}$} & \multirow{2}{*}{$\begin{array}{c}\text { NRC } \\
\text { rizomas/pl.) }\end{array}$} & RM & FG & FM & FP & REF \\
\hline & & \multicolumn{2}{|c|}{ t ha $^{-1}$} & & & \multicolumn{5}{|c|}{ t ha $^{-1}$} \\
\hline$\overline{\mathrm{SOL}}$ & - & 63,12 & 41,69 & 106,47 & 11,92 & 16,60 & 20,33 & 17,51 & 3,84 & 4,84 \\
\hline $18 \%$ & & $57,02^{\text {ns }}$ & $34,84^{\mathrm{ns}}$ & $111,67^{\text {ns }}$ & $9,08^{*}$ & $20,46^{\mathrm{ns}}$ & $16,56^{\mathrm{ns}}$ & $13,13^{\text {ns }}$ & $5,15^{\text {ns }}$ & $1,71^{*}$ \\
\hline $30 \%$ & Ciclo todo & $56,84^{\text {ns }}$ & $31,36^{*}$ & $116,22^{\text {ns }}$ & $8,17^{*}$ & $22,44^{*}$ & $15,46^{\mathrm{ns}}$ & $12,68^{*}$ & $3,22^{\text {ns }}$ & $3,04^{*}$ \\
\hline $50 \%$ & & $54,70^{\text {ns }}$ & $27,89^{*}$ & $91,13^{\text {ns }}$ & $9,17^{*}$ & $24,93^{*}$ & $10,58^{*}$ & $10,70^{*}$ & $6,61^{*}$ & $1,88^{*}$ \\
\hline $18 \%$ & & $55,09^{\text {ns }}$ & $35,00^{\text {ns }}$ & $98,08^{\mathrm{ns}}$ & $10,00^{\text {ns }}$ & $18,17^{\text {ns }}$ & $12,68^{\mathrm{ns}}$ & $14,95^{\text {ns }}$ & $7,34^{*}$ & $1,96^{*}$ \\
\hline $30 \%$ & Inicial & $49,57^{*}$ & $28,96^{*}$ & $119,34^{\text {ns }}$ & $7,46^{*}$ & $18,49^{\text {ns }}$ & $13,67^{\mathrm{ns}}$ & $11,37^{*}$ & $3,92^{\text {ns }}$ & $2,11^{*}$ \\
\hline $50 \%$ & & $43,64^{*}$ & $23,87^{*}$ & $97,09^{\text {ns }}$ & $7,37^{*}$ & $16,51^{\mathrm{ns}}$ & $10,46^{*}$ & $10,00^{*}$ & $3,40^{\text {ns }}$ & $3,26^{*}$ \\
\hline $18 \%$ & & $52,02^{\text {ns }}$ & $32,01^{\text {ns }}$ & $106,83^{\text {ns }}$ & $9,08^{*}$ & $16,01^{\text {ns }}$ & $14,42^{\text {ns }}$ & $13,56^{\text {ns }}$ & $4,03^{\text {ns }}$ & $4,00^{\text {ns }}$ \\
\hline $30 \%$ & Intermediário & $43,56^{*}$ & $24,70^{*}$ & $116,20^{\text {ns }}$ & $6,67^{*}$ & $16,69^{\text {ns }}$ & $9,99^{*}$ & $12,15^{\star}$ & $2,56^{\mathrm{ns}}$ & $2,16^{*}$ \\
\hline $50 \%$ & & $41,86^{*}$ & $22,31^{*}$ & $96,06^{\text {ns }}$ & $7,04^{*}$ & $17,43^{\text {ns }}$ & $6,70^{*}$ & $11,70^{*}$ & $3,89^{\text {ns }}$ & $2,12^{*}$ \\
\hline $18 \%$ & & $49,80^{*}$ & $27,03^{*}$ & $120,50^{\text {ns }}$ & $6,83^{*}$ & $18,62^{\mathrm{ns}}$ & $12,99^{\text {ns }}$ & $10,70^{*}$ & $3,33^{\text {ns }}$ & $4,14^{\mathrm{ns}}$ \\
\hline $30 \%$ & Final & $48,20^{*}$ & $27,83^{*}$ & $114,16^{\mathrm{ns}}$ & $7,46^{*}$ & $16,58^{\mathrm{ns}}$ & $15,48^{\text {ns }}$ & $8,92^{*}$ & $3,42^{\text {ns }}$ & $3,79^{\text {ns }}$ \\
\hline $50 \%$ & & $50,69^{*}$ & $25,80^{*}$ & $92,73^{\text {ns }}$ & $9,33^{*}$ & $18,74^{\mathrm{ns}}$ & $11,62^{\mathrm{ns}}$ & $9,17^{*}$ & $5,01^{\text {ns }}$ & $6,15^{\mathrm{ns}}$ \\
\hline Média geral & & 51,24 & 29,48 & 106,65 & 8,43 & 18,59 & 13,29 & 12,04 & 4,29 & 3,17 \\
\hline CV (\%) & & 11,74 & 15,57 & 10,79 & 14,71 & 14,48 & 28,35 & 18,17 & 27,89 & 21,80 \\
\hline
\end{tabular}

* e ns: respectivamente significativo e não-significativo a 5\% de probabilidade, em relação ao controle, pelo teste de Dunnett (* and ns: respectively significant and not significant, $5 \%$ of probability in relation to standard, Dunnet test).

mero de rizomas comerciáveis por planta (NRC), bem com de produtividade de rizomas comerciáveis (PC), em relação ao controle (Tabela 3). A menor PC do tratamento de $30 \%$ sombra foi devida à menor produtividade de filho médio (FM), enquanto sob $50 \%$ de sombra a menor PC foi devida às menores produtividades de FG e FM, apesar de ter tido maior produtividade de FP. O efeito adverso da sombra, na menor intensidade (18\%) durante o ciclo todo foi menor e, exceto para NRC e REF, não significativo, o que indica tolerância da planta de taro a essa intensidade de restrição de luz. Portanto, plantas sob sombreamento durante o ciclo todo, sobretudo nas maiores intensidades (30\% e 50\%), além de investirem mais assimilados para crescimento de parte aérea (área foliar e comprimento de pecíolo (Figura 2; Tabela 1) acumularam mais reservas no rizoma-mãe, em detrimento dos rizomas-filho (Figura 3; Tabelas 2 e 3). Em taioba, Spence (1970) sugeriu que diminuição da AF pode reduzir o crescimento de rizoma-mãe. Caesar (1980) também verificou, na cv. Trinidade Eddoe, maior produtividade de rizomas comerciáveis em plantas cultivadas sob sol. Todavia, Oliveira (2004) constatou em taro 'Japonês', sob condições de elevadas irradiância e temperatura, diminuição de queimaduras foliares e bom desenvolvimento e produção de rebentos com o nível de restrição de luz de até $50 \%$, o que pode ser explicado, em parte, pela redução da temperatura proporcionada pela malha, como observado na Figura 1. Entretanto, na intensidade de $75 \%$ de restrição de luz, esse autor também observou maior investimento em produção de biomassa de parte aérea em detrimento de rizomas.

Exceto o tratamento de $18 \%$ de sombra nas fases inicial e intermediária, as demais intensidades e épocas de sombreamento reduziram a produtividade total (PT) e comercial (PC) de rizomas. A redução da $\mathrm{PC}$ e, conseqüentemente, da PT ocorreu em razão do menor NRC e, portanto, da sua massa média. Na intensidade de $50 \%$ de sombra nos períodos inicial e intermediário, as reduções da PC e PT foram devidas às menores produtividades das classes FG e FM, enquanto no período final foi devida a menor produtividade da classe FM. Na intensidade de 30\% de sombra as reduções da PC e PT foram devidas às reduções das produtividades de FG e FM no período intermediário e de FM nos períodos inicial e final.

Dentre os tratamentos de sombra, a intensidade de $18 \%$ foi a que menos afetou as produtividades PT e PC, sobretudo quando aplicado no ciclo todo de cultivo e nos períodos inicial e intermediário, quando não diferiu do controle (Tabela 3). Apesar do taro ser cultivado a pleno sol, os resultados evidenciam certa plasticidade da planta em ajustar-se às condições de menor irradiância, possivelmente em razão de ser originada de ambientes sombreados (Rubatzky \& Yamaguchi, 1997; Imbert et al., 2004).

Maiores intensidades de sombra (30 e 50\%) durante o ciclo todo proporcionaram menores valores de PC, NRC, FG (50\%), FM e REF e maior de RM e de FP (50\%) (Tabela 3). Portanto, intensidades de sombra acima de $18 \%$ durante o ciclo todo não seriam desejáveis visto que RM e FP alcançam baixa cotação no comércio (Puiatti, 2002).

Embora as plantas tenham apresentado recuperação parcial da parte aérea após as mudanças de períodos de som- 
bra (Figura 2; Tabela 1), as PT, PC e das classes de rizomas-filho, sobretudo da classe FM e nos tratamentos com maiores intensidades de sombra (30\% e $50 \%)$, foram afetadas em relação ao controle (Tabela 3). De acordo com Hashad et al. (1956), em taro, os açúcares sintetizados no limbo são translocados para os rizomas passando por um “armazenamento temporário” no pecíolo. Dessa forma, o armazenamento de reservas nos rizomas é altamente dependente da integridade das estruturas aéreas (limbo e pecíolo), e qualquer alteração morfofisiológica dessas poderá afetar a síntese, quantidade e velocidade de translocação dos assimilados, repercutindo no crescimento e produtividade de rizomas.

O sombreamento nos períodos inicial (0-90 DAP), intermediário (90-180 DAP) e final (180-270 DAP), promoveu, em relação à testemunha, redução significativa nas PT e PC, sendo a redução do NRC um dos efeitos mais marcantes com reflexo, principalmente, na produtividade de FM nas três fases e de FM e FG na fase intermediária, demonstrando que a restrição de luz, sobretudo no período intermediário, limitou a fonte resultando em menor quantidade de fotoassimilados para serem distribuídos aos rizomas-filho. Não era esperado, entretanto, que a sombra implementada na fase final (180-270 DAP) afetasse tanto a produtividade de rizomas, uma vez que as plantas já estariam entrando na fase de maturação e a limitação de fotoassimilados, devida ao sombreamento, seria menos danosa (Tabela 3). A redução no metabolismo das plantas na fase final, em razão do abaixamento da temperatura promovido pela malha (Figura 1), poderia ser uma explicação para o observado.

Os resultados de produtividade de rizomas foram bastante elevados, mesmo aqueles submetidos à restrição de luz. Na literatura, informações sobre a produtividade total variam de 6,6 a 63,3 $\mathrm{t} \mathrm{ha}^{-1}$, dependendo da variedade, local, época e densidade de plantio e manejo da fertilização (Plucknett \& de La Peña, 1971; Ishimurai Sáes et al., 1994; Goenaga \& Chardon, 1995; Pandey \& Dobhal, 1997). No cultivo a pleno sol, Carmo \& Ferrão (2000) obtiveram, para

Tabela 4. Equações de regressão ajustadas às variáveis produtividade total (PT) e comerciável (PC), massa média de rizomas comerciáveis (MRC), número de rizomas comerciáveis por planta (NRC), produtividade rizomas mãe (RM) e de filhos grande (FG), médio (FM), pequeno (FP) e refugo (REF), de plantas de taro 'Japonês', na colheita aos 270 DAP, em função das intensidades de sombreamento $(\mathrm{X})$ no ciclo todo, e os respectivos coeficientes de determinação (regression equations adjusted to the variables total yield (PT) and commercial yield (PC), average mass of commercial rhizomes (MRC), number of commercial rhizomes/ plant (NRC), yield of mother rhizomes (RM) and great rhizomes (FG), intermediate (FM), small (FP) and discard (REF), of taro 'Japonês' plants, harvested 270 days after planting date, depending on the shading intensity (X) on all cycle and the respective determination coefficients). Viçosa, UFV, 2005.

\begin{tabular}{|c|c|c|}
\hline Variáveis & Equações ajustadas & $\mathbf{r}^{2}$ \\
\hline PT (t ha-1) & $Y=61,804-0,158^{*} X$ & 0,8428 \\
\hline $\mathrm{PC}\left(\mathrm{t} \mathrm{ha} \mathrm{a}^{-1}\right)$ & $Y=40,689-0,275^{* *} X$ & 0,9628 \\
\hline MRC (g/rizoma) & $Y=106,37$ & - \\
\hline NRC (rizomas/planta) & $Y=11,938-0,224^{*} X+0,0034^{*} X^{2}$ & 0,9981 \\
\hline $\mathrm{RM}\left(\mathrm{t} \mathrm{ha}^{-1}\right)$ & $Y=17,041+0,166^{* *} X$ & 0,9805 \\
\hline FG $\left(\mathrm{t} \mathrm{ha}^{-1}\right)$ & $Y=20,383-0,189^{* *} X$ & 0,9823 \\
\hline $\mathrm{FM}(\mathrm{t} \mathrm{ha-1})$ & $Y=16,689-0,129^{*} X$ & 0,9016 \\
\hline $\mathrm{FP}\left(\mathrm{t} \mathrm{ha} \mathrm{a}^{-1}\right)$ & $Y=4,705$ & - \\
\hline $\operatorname{REF}\left(\mathrm{t} \mathrm{ha}^{-1}\right)$ & $Y=2,869$ & - \\
\hline
\end{tabular}

* e $\mathrm{e}^{* *}$ : respectivamente significativo a 5 e $1 \%$ de probabilidade, pelo teste "t" $(* ; * * ; * * *$ : respectively significant at 5; 1 and $10 \%$ probability, "t" test).

o clone 'Japonês', 32,1 e 26,8 t ha-1 e Puiatti et al. (2000), para o 'Chinês, 21,2 e 14,6 t ha-1 de produtividade de rizomas totais e comerciáveis, respectivamente.

Considerando-se apenas os tratamentos que receberam sombreamento nas quatro intensidades (sol; 18; 30 e $50 \%$ ) durante o ciclo todo, as equações de regressão foram ajustadas para características de produção de rizomas (Tabela 4). As produtividades PT, PC, FG e FM apresentaram redução linear com o aumento da intensidade de sombra, com reduções de 158; 275; 189 e $129 \mathrm{~kg} \mathrm{ha}^{-1}$ por aumento de unidade de sombreamento, respectivamente; por sua vez, a produtividade de rizoma-mãe apresentou incremento linear ao sombreamento, com aumento de $166 \mathrm{~kg}$ $\mathrm{ha}^{-1}$ por aumento de unidade sombreada. A MRC e produtividades de FP e REF mantiveram-se constantes com a intensidade de sombra, com 106,37 g/ rizoma e 4.705 e $2.869 \mathrm{~kg} \mathrm{ha}^{-1}$, respectivamente. O NRC exibiu resposta quadrática, com máximo estimado de 8,25 rizomas/planta na intensidade de 32\% de sombra (Tabela 4).

As plantas podem apresentar diferentes respostas fisiológicas e, conseqüentemente, agronômicas não só sob o aspecto quantitativo, mas também qualitativo, relacionado às condições de ambiente e de práticas fitotécnicas. Uma das explicações para os resultados obtidos sob sombreamento pode estar relacionada com a diminuição de fotoassimilados para os rizomas-filho, sobretudo quando se intensifica o sombreamento. Para a cultura do taro 'Japonês' deve-se, portanto, evitar o sombreamento com intensidade acima de $18 \%$, mesmo que parcialmente vez que, em qualquer período, o sombreamento acima dessa intensidade promoveu redução significativa na produção de rizomas comerciáveis. O tratamento $18 \%$ de sombra durante o ciclo todo e nos períodos inicial e intermediário revelou-se menos prejudicial, com a PC não diferindo da testemunha. Os resultados obtidos evidenciam que plantas de taro crescendo sob forte restrição de luz privilegiam o investimento de fotoassimilados na formação da parte área (pecíolo), e do rizoma-mãe, em detrimento dos rizomas-filho. Todavia, essas também foram eficientes em acumular MS nos rizomas-filho sob $18 \%$ de sombreamento, o que vislumbra a possibilidade de sucesso da associação da cultura do taro com espécies dominantes que promovam sombreamento de até $18 \%$ durante o ciclo todo ou nos 2/3 iniciais do ciclo da cultura. Portanto, na associação de cul- 
turas de maior porte com a cultura do taro, a cultura associada poderá promover sombreamento com intensidade de até $18 \%$, quer seja durante o ciclo todo ou nos períodos inicial e intermediário, pois não causaria diminuição significativa de produção de rizomas PC.

\section{REFERÊNCIAS}

BARRELLA TP. 2003. Crescimento e produção de mandioquinha-salsa (Arracacia xanthorrhiza Bancroft) sob níveis e períodos de sombreamento artificial. Viçosa: UFV. 46p (Tese mestrado).

CAESAR K. 1980. Growth and development of Xanthosoma and Colocasia under different light and water supply conditions. Field Crops Research 3: 235-244.

CAIGER S. 1986. Effect of shade on yield of taro cultivars in Tuvalu. Alafua Agricultural Bulletin 11: 66-68.

CARMO CAS; FERRÃO MAG. 2000. Comportamento de clones de inhame na região centro-serrana do Estado do Espírito Santo. Horticultura Brasileira 18: 591-593 (Suplemento Julho).

FAO - 2006. http://faostat.fao.org/faostat. Acessado em 28 de abril de 2006.

GAWRONSKAH; DWELLE RB. 1989. Partitioning of photoassimilates by potato plants (Solanum tuberosum L.) as influence by irradiance: I. Partitioning patterns in cultivar Russet Burbank grown under high and low irradiance. American Potato Journal 66: 201-213.

GOENAGA R. 1995. Accumulation and partitioning of dry matter in taro [Colocasia esculenta (L.) Schott]. Annals of Botany 76: 337-341.

GOENAGA R; CHARDON U.1995. Growth, yield and nutrient uptake of taro grown under upland conditions. Journal of Plant Nutrition 18: 1037-1048.

GOENAGA R. 1994. Partitioning of dry matter in tanier (Xanthosoma spp.) irrigated with fractions of evapotranspiration. Annals of Botany 73: 257-261.

GOENAGA R; SINGH U. 1992. Accumulation and partition of dry matter in tanier (Xanthosoma spp.). In: SINGH, U. (ed.). Proceedings of the Workshop on taro and tanier modeling. Honolulu, Hawaii: College of Tropical Agriculture and Human Resources. p. 37-43.
HASHAD MN; STINO KR; EL-HINNAMY S.I. 1956. Transformation and translocation of carbohydrates in taro plants during growth. Annals of Agricultural Science 1: 269-276.

HENDRY GAF; PRICE AH. 1993. Stress indicators: chlorophylls and carotenoids. In: HENDRY GAF; GRIMEJP. (eds). Methods in comparative plant ecology. London: Chapman \& Hall. p.148-152.

HOLE CC; DEARMAN J. 1990. Partition of ${ }^{14} \mathrm{C}$ assimilate between organs and fractions of contrasting varieties of carrot during initiation of the storage root. Journal of Experimental Botany 41: 557-564.

IMBERT D; SAUR E; BONHEME I; ROSEAU V. 2004. Traditional taro (Colocasia esculenta) cultivation in the swamp forest of Guadeloupe (FWI.): Impact on forest structure and plant biodiversity. Revue d'Ecologie 59: 181-189.

ISHIMURAI SÁES LA; LORENZI JO; MONTEIRO DA. 1994. Efeito de cinco níveis de adubação NPK na produção de inhame no Vale do Ribeira-SP. In: ENCONTRO NACIONAL SOBRE A CULTURA DO INHAME, I. 1987. Anais... Viçosa: UFV. p. 1-3.

LARCHER W. 2000. Ecofisiologia vegetal. São Carlos: RiMa. 531 p.

MASCARENHAS MHT; RESENDE LMA. 2002. Situação atual e perspectivas das culturas do taro e do inhame no estado de Minas Gerais. In: CARMO CAS (ed). Inhame e taro: sistemas de produção familiar. Vitória: Incaper. p. 61-71.

NAVES VL; ALVARENGA AA; OLIVEIRA LEM. 1994. Comportamento estomático de mudas de três espécies florestais submetidas a diferentes níveis de radiação fotossinteticamente ativa. Ciência e Prática 18: 408-418.

OLIVEIRA FL. 2004. Alternativas para o manejo orgânico do taro (Colocasia esculenta L. Schott) em condições edafoclimáticas no estado do Rio de Janeiro. Seropédica: UFRRJ. 90p. (Tese doutorado).

PANDEY G; DOBHAL VK. 1997. Multivariate analysis in taro (Colocasia esculenta (L.) Schott). Indian Journal of Genetics and Plant Breeding 57: 262-265.

PEDRALLI G; CARMO CAS; CEREDA M; PUIATTI M. 2002. Uso de nomes populares para as espécies de Araceae e Dioscoreaceae no Brasil. Horticultura Brasileira 20: 530-532.
PEREIRA FHF. 2006. Crescimento da planta, produção e qualidade de frutos de melões Amarelo e Charentais cultivados sob diferentes malhas. Viçosa: UFV. 60 p. (Tese doutorado).

PLUCKNETT DL; La PEÑA RS. 1971. Taro production in Hawaii. World Crops 23: 244249.

PUIATTI M. 2002. Manejo da cultura do taro. In: CARMO CAS (ed). Inhame e taro: sistema de produção familiar. Vitória: Incaper. p. 203252.

PUIATTI M; FÁVERO C; FINGER FL; GOMES JM. 2000. Crescimento e produtividade de inhame e milho doce em cultivo associado. Horticultura Brasileira 8: 24-30.

PUIATTI M; GREENMAN S; KATSUMOTO R; FÁVERO C. 1992. Crescimento e absorção de macronutrientes pelo inhame 'Chinês' e 'Japonês’. Horticultura Brasileira 10: 89-92.

PUIATTI M; CAMPOS JP; CASALI VWD; CARDOSO AA; CRUZ R. 1990. Sistema de colocação do bagaço de cana-de-açúcar e capim gordura, na cultivar de inhame Chinês. Horticultura Brasileira 8: 14-16.

ROYCHOWDHURY S. 1995. Leaf area development in Colocasia and its relationship with yield. Indian Journal of Plant Physiology 38: 305-308.

RUBATZKY VE; YAMAGUCHI M. 1997. Word vegetables. Principles, production, and nutritive values. 2. ed. New York: Chapman \& Hall. 843 p.

SANTOS RHS. 1998. Interações interespecíficas em consórcio de olerícolas. Viçosa: UFV. 129p. (Tese doutorado).

SOUZA JRP; MEHL HO; RODRIGUES JD; PEDRAS JF. 1999. Sombreamento e o desenvolvimento e produção de rabanete. Scientia Agricola 56:987-992.

SPENCE JA. 1970. Growth and development of tanier (Xanthosoma spp.). In: PROCEEDINGS OF THE INTERNATIONAL SYMPOSIUM FOR TROPICAL ROOT AND TUBER CROPS. Hawaii: p. 47-52.

TAIZ L; ZEIGER E. 1998. Plant physiology. 2.ed. Sunderland, Massachusetts: Sinauer Associates, Inc., Publishers. 792 p. 